\title{
Amazônia: mineração, tributação e desenvolvimento regional*
}

Maurílio de Abreu Monteiro - Professor do Núcleo de Altos Estudos Amazônicos (NAEA), da Universidade Federal do Pará (UFPA)

\section{Resumo}

Neste artigo, apresentam-se algumas lógicas que fundamentam a tributação, a cobrança de royalties e o estabelecimento de favores fiscais, analisando-se as possibilidades de usar essas compensações para favorecer a articulação da mineração com dinâmicas de enraizamento social do desenvolvimento. Conclui-se que na Amazônia não há políticas públicas de concessão de favores fiscais que induzam as empresas mineradoras a adotar comportamentos que contribuam para o desenvolvimento regional. Constata-se também que as alíquotas de royalties fixadas no Brasil são relativamente baixas, o que se deve mais a uma apropriação desigual do poder político do que a uma restrição microeconômica.

\section{Abstract}

This article examines the founding basis of taxation, royalty charges, and the concession of fiscal benefits, analyzing the compensations aimed at favoring the articulation between mining and the dynamics of socially rooted development. The author arrives at the conclusion that, in Amazonia, there are no public policies regarding fiscal benefit concessions that can lead mining companies to take actions towards regional development. Royalty rates in Brazil are relatively low due to unequal appropriation by the political powers rather than to microeconomic restrictions.

\section{Palavras-chave:}

Mineração, tributação, royalties, desenvolvimento regional.

\section{Keywords}

Mining, taxation, royalties, regional development.

*A elaboração deste artigo contou com o apoio do CNPq. 


\section{INTRODUÇÃO}

Considerando-se razões geológicas, históricas, mercadológicas e logísticas, devem-se ampliar as reflexões acerca das condições em que é possível converter os recursos minerais da Amazônia em vetores de desenvolvimento socialmente enraizado, em especial porque, no contexto mundial, o Brasil ocupa uma das principais posições no que se refere à possibilidade de atração de investimentos no setor (Gráfico 1). Além disso, na primeira década deste século, a atividade mineradora será responsável pelo maior volume de investimentos na fração oriental da região.

Deve-se levar em conta que o resultado social e econômico da mineração, em termos regionais, tem sido o reforço de dinâmicas que favoreceram a concentração da renda, a homogeneização dos processos produtivos e a valorização pouco qualificada do capital natural da região. No que concerne à interação da mineração com a socioeconomia regional, constatam-se dificuldades para, a partir dessa atividade, construir-se redes de relações sociais, econômicas, políticas e ambientais que sejam impulsionadoras de um desenvolvimento regional baseado na edificação de sistemas produtivos capazes de alimentar localmente dinâmicas de inovação que, por sua vez, favoreçam o estabelecimento de processos produtivos cujo diferencial de competitividade não esteja tão-somente na utilização, a baixo custo, de recursos e serviços ambientais da região.

Uma das possibilidades de se articular a atividade de mineração com dinâmicas mais gerais de desenvolvimento é o uso de linkages fiscais. Dessa forma, a sociedade, por meio das estruturas estatais, pode capturar parte do valor gerado pela mercantilização de recursos minerais, o que se efetiva, em geral, graças à tributação que incide tanto sobre a extração e a comercialização, quanto sobre o lucro auferido pelas empresas responsáveis pela valorização de recursos minerais. Contudo, o volume da receita tributária decorrente dessa atividade sofre reduções em decorrência da sistemática renúncia fiscal. Isso decorre do fato de que o Estado nacional e as unidades federadas - para incentivar a valorização de recursos minerais da região - findam por reduzir a incidência de impostos, taxas, contribuições e tributos de outras ordens ou mesmo por estabelecer preços públicos e compensações financeiras, limitando assim a capacidade estatal de capturar parte do valor gerado pela mineração.

Este artigo discute algumas das lógicas que fundamentam a tributação (lato sensu) e o estabelecimento de favores fiscais e analisa as possibilidades de usar essas compensações para favorecer a articulação da mineração com dinâmicas de enraizamento social do desenvolvimento. 


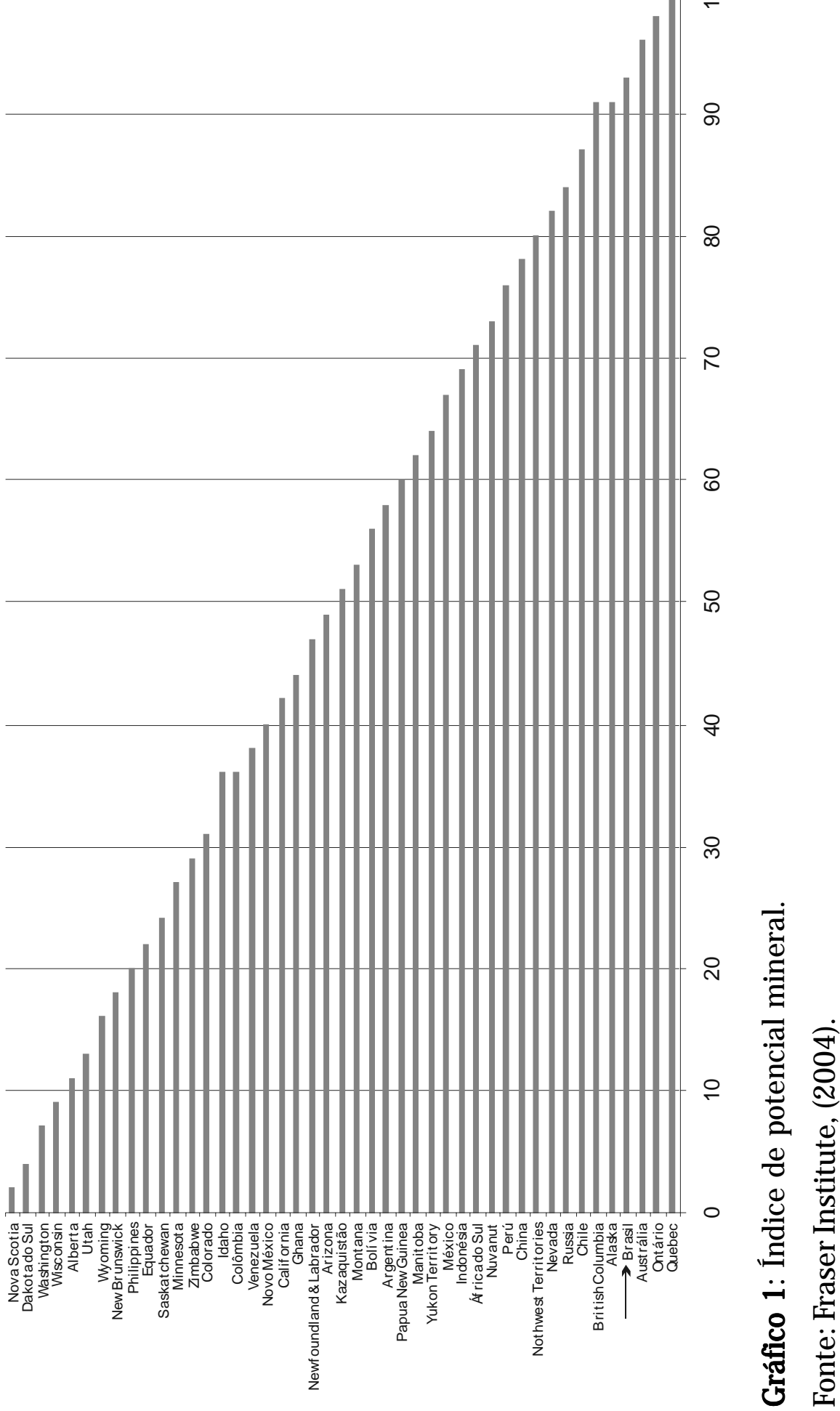




\section{1 - INCENTIVOS FISCAIS VINCULADOS À DIMENSÃO DOS INVESTIMENTOS}

Atividades que visam a valorização de recursos minerais para atender à demanda global são intensivas em capital. Requerem elevados gastos com pesquisa mineral para a localização de novos jazimentos e para o desenvolvimento do empreendimento mineiro. Segundo Parsons (2000, p. 8), o governo de Canadá, por exemplo, calculou que são gastos, a cada ano, aproximadamente US\$ 586 milhões tão-somente em pesquisas direcionadas à prospecção mineral para substituir as minas que são explotadas somente naquele país. São elevados também os custos da montagem da estrutura necessária à exploração de um corpo mineiro de classe mundial, cuja viabilidade econômica está intrinsecamente ligada à dimensão dos depósitos de minérios, que devem ser cada vez maiores. Com efeito, a crescente extração do recurso em áreas mais remotas em relação ao seu local de demanda, tanto por causa da expansão da demanda global quanto pela depleção de reservas mais acessíveis, requer a edificação de infra-estrutura e uma logística que só são compatíveis com minas cada vez maiores (BARHAM; BUNKER; O'HEARN, 1994).

Estudo de Mackenzie (1998), com base na análise de depósitos minerais do Chile, indicou que o tamanho médio de um depósito de metal básico é de 171 milhões de toneladas e, no caso de metais preciosos, de 19 milhões de toneladas. Os depósitos de minério de ferro em Carajás são de 17,23 bilhões de toneladas, os de cobre da mina do Sossego, também na região de Carajás, são de 191 milhões de toneladas, os de bauxita do Rio Trombetas são de 674 milhões; demandaram investimentos de US\$ 3,3 bilhões, US\$ 413 milhões e US\$ 1,2 bilhão respectivamente. Os custos dos empreendimentos voltados para a explotação de minas de classe mundial pode alcançar, assim, mais de US\$ 3 bilhões. Além disso, a implantação de uma mina requer a compra de grande quantidade e diversidade de equipamentos; em função do nível de especialização desses equipamentos, em geral é necessário recorrer a fornecedores igualmente especializados e dispersos pelo mundo.

Como a exploração mineral é uma atividade que exige o investimento de elevadas quantias de capitais, cujo retorno comporta riscos significativos, as empresas mineradoras recorrentemente defendem a necessidade de ajustes nos sistemas fiscais para torná-los aptos a incorporar essas especificidades. Esse argumento ganhou crescente força na modelagem dos sistemas tributários, em especial nos 
anos 80 e 90 do século XX, momento histórico no qual tinha mais força o discurso liberal. É possível, também, constatar a existência de negociações entre mineradoras e governos que resultam em regimes fiscais especiais.

Uma das principais justificativas para a elaboração de exceções fiscais é o fato de que os custos do capital envolvido na implantação do empreendimento mineiro tendem a ser menores à medida que mais rapidamente seus financiadores forem reembolsados. Na ótica do capital financeiro, em se tratando de negócio de risco, quanto menos dilatado for o tempo de exposição do capital, menor será o índice que representará esse fator na composição dos custos de remuneração da operação (Figura 1).

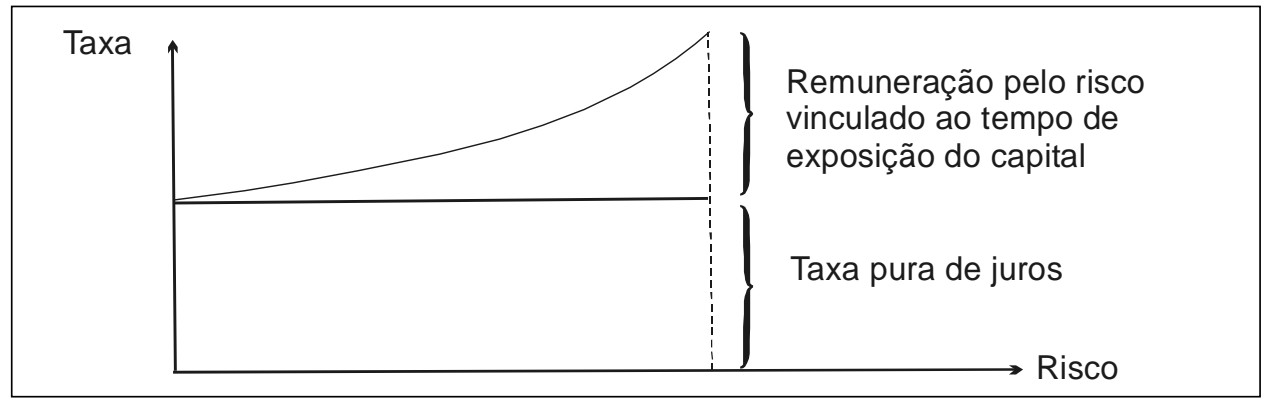

Figura 1: Representação esquemática da alteração da taxa de juros em decorrência do tempo de exposição do capital financeiro. Fonte: Elaboração do autor.

Assim, quando o empreendimento apresenta capacidade de reduzir mais rapidamente as dívidas relativas à implantação do empreendimento, o empreendedor mineiro tende a obter classificação de risco dos empréstimos mais favorável e, conseqüentemente, taxas de financiamento menores. Por isso, o minerador procura destinar o máximo de suas rendas iniciais para abater dívidas e reduzir os custos financeiros. Mackenzie (1998), por seu turno, estima que, em média, uma taxa de $10 \%$ é o custo de capital aceitável para a exploração de um depósito mineral.

Ao construir a equação relativa à destinação das receitas originárias dos primeiros anos de operação do empreendimento mineiro, a empresa mineradora procura maximizar a amortização de financiamentos e, para isso, busca fontes. Inserem-se aí as negociações com os governos visando a obter a redução, por determinado período de tempo, da incidência de tributos sobre o empreendimento (tax holidays). 
Tome-se, por exemplo, o caso da exploração da jazida de cobre do Sossego, na Amazônia oriental. Nela a Companhia Vale do Rio Doce (CVRD) investirá US\$ 413 milhões; serão necessários dois anos para que se inicie a produção e pelo menos mais dois para que se atinja a produção prevista de 350 mil toneladas de concentrado de cobre por ano (140 mil toneladas de cobre), o que permitirá a lavra por um período de 17 anos. Levando-se em conta a previsão de US\$1,35 para o preço de venda da tonelada de concentrado de cobre e a indicação de que os custos operacionais, os anunciados pela empresa, serão de 0,32 US $\$ / l b$, que equivalem a $0,71 \mathrm{US} \$ / \mathrm{kg}$, a mina terá um custo operacional médio equivalente a $52,22 \%$ do preço de venda do concentrado de cobre. A esses custos somar-se-ão outros, que se podem estimar em $10 \%$ do faturamento bruto da mina. Assim, a mina, no quarto ano do projeto, quando, provavelmente, atingirá o volume de exploração projetada, propiciará lucro, antes da tributação sobre a renda, de aproximadamente de US\$ 177 mil/ano (Tabela 1). É com essa receita que a companhia deverá pagar os financiadores do projeto. Sendo maior o prazo de pagamento, maiores serão os juros cobrados sobre a parte do capital que não é da empresa. Assim, na expressão da lucratividade do empreendimento, tem grande relevância a possibilidade de obtenção de redução na alíquota de imposto de renda, pois essa redução terá repercussão não somente no volume de recursos que a empresa mineradora alcançará, mas também na taxa de financiamento da parte do capital de terceiros utilizado para financiar o empreendimento mineiro (Figura 1).

Tabela 1: Estimativa de faturamento e de lucro anuais da mina do Sossego na etapa de produção plena (em US\$).

\begin{tabular}{|lrr|}
\hline \multicolumn{1}{|c}{ Elementos } & \multicolumn{1}{c|}{ Valores } & Percentuais \\
\hline Receita bruta & 470.000 .000 & $100 \%$ \\
Despesas operacionais & -245.434 .000 & $-52.22 \%$ \\
Outras deduções da receita bruta & -47.000 .000 & $-10.00 \%$ \\
Receita líquida & 177.566 .000 & $37.78 \%$ \\
Imposto de renda e contribuição social & 58.596 .780 & $12.47 \%$ \\
Lucro anual & 118.969 .220 & $25.31 \%$ \\
\hline
\end{tabular}

Fonte: Elaboração do autor, com base em informações da Diretoria de Não-Ferrosos da CVRD.

No caso da mina do Sossego, levando-se em conta a necessidade de realização, nos dois primeiros anos (2003 e 2004), de investimentos de US\$ 413 milhões, a redução de 75\% na alíquota do Imposto de Renda, nos primeiros 10 anos de operação do empreendimento, permitiria que 
o tempo de recuperação do investimento fosse de 5 anos; se não houver essa redução de alíquota, o tempo de recuperação do empreendimento subiria para 7 anos. Considerando-se uma suposta relação equity/debt de $50 \%$ - ou seja, se a metade dos recursos necessários à implantação fosse originária de empréstimos - e assumindo-se que a parcela oriunda de financiamentos de terceiros poderia ser remunerada a uma taxa de juros de $8 \%$ a.a., mas se o tempo de recuperação do capital fosse ampliado para 7 anos, a taxa de juros seria elevada para 12\% a.a (Gráfico 2).

Em relação à rentabilidade da mina do Sossego, a simulação da não existência de favores fiscais vinculados ao IR resultaria em uma taxa média de retorno de $21.23 \%$; no caso da existência dessa redução, a taxa de retorno atingiria $32.75 \%$, o que, estima-se, significaria uma diferença nos lucros acumulados pelo empreendimento de mais de US\$ 450 milhões (Gráfico 2). Nesses termos, a existência de uma política tributária diferenciada para a renda auferida por um empreendimento mineiro tem grande relevância para a sua lucratividade. Na Amazônia brasileira, esses incentivos fiscais têm caráter contratual, sendo aprovados individualmente para cada empreendimento; presentemente, incluem a redução da alíquota de imposto de renda em até $75 \%$. Eles eram estabelecidos no âmbito da então Superintendência para o Desenvolvimento da Amazônia (SUDAM), atualmente da Agência de Desenvolvimento da Amazônia (ADA) .

No dizer de Otto (2000), a redução da incidência tributária nos primeiros anos de um empreendimento mineiro como forma de compensação pela envergadura dos investimentos é uma prática de alguns países (Quadro 1). Segundo o autor (2000, p. 13), alguns investidores consideram esse tipo de incentivo fiscal como determinante para a implementação de um empreendimento voltado para a exploração mineral. Todavia, para esse favor fiscal, o Estado não tem sido capaz de estabelecer contrapartidas a serem apontadas pelas empresas, no que se refere ao reforço da dinamização do desenvolvimento local.

Parsons (2000) mostra que o Canadá, por exemplo, oferece regimes de tributação para atividades de mineração que permitem ao minerador recuperar seus custos de capital antes do pagamento do imposto de renda. Essa recuperação de custo de capital é obtida por meio da permissão da realização de deduções de até $100 \%$ de imposto devido sobre os gastos de capital efetuados durante o período de pré-produção. Isso permite que nos primeiros anos de produção haja uma redução de pagamentos de imposto de renda, o que possibilita ao empreendimento resgatar mais rapidamente dívidas decorrentes de sua instalação. Há também políticas tributárias que prescrevem taxas de depreciação relativamente elevadas, quando comparadas, por exemplo, às dos Estados Unidos e da China (Quadro 2). 


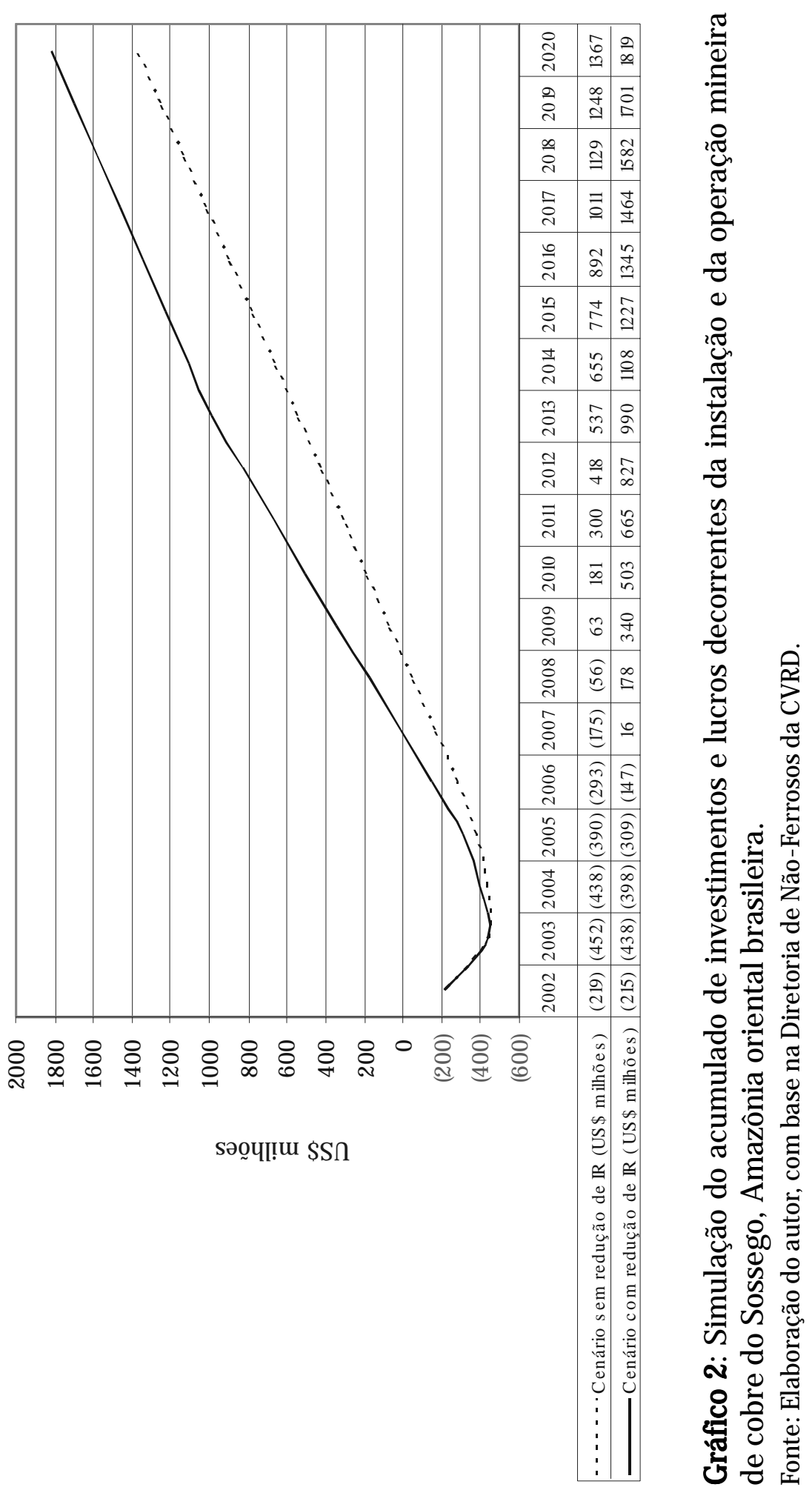




\begin{tabular}{l|c}
\hline \multicolumn{1}{c|}{ País } & Taxa holidays \\
\hline África do Sul & Sim \\
\hline Argentina & Sim \\
\hline Austrália (Western Austrália) & Sim \\
\hline Bolívia & Sim \\
\hline Brasil (Amazônia legal) & Sim \\
\hline Canadá (Ontário) & Sim \\
\hline Chile & Não \\
\hline China & Sim \\
\hline Costa do Marfim & Sim \\
\hline Equador & Sim \\
\hline Estados Unidos (Colorado) & Sim \\
\hline Filipinas & Sim \\
\hline Gana & Sim \\
\hline Guiana & Sim \\
\hline Indonésia & Sim \\
\hline Kazaquistão & Sim \\
\hline México & Nã̃o \\
\hline Papua Nova Guiné & Não \\
\hline Peru & Nã̃o \\
\hline Polônia & Sim \\
\hline Suriname & Sim \\
\hline Tanzânia & Sim \\
\hline
\end{tabular}

Quadro 1: Existência de períodos de isenção ou de redução de tributos para empreendimentos minerais.

Fonte: Andrews-Speed (2000); Mackenzie (1998); Otto ( 2000, 2001); Otto; Cordes (2002); Parsons (1998, 2000).

\begin{tabular}{l|c}
\hline \multicolumn{1}{c|}{ País } & Depreciação \\
\hline Africa do Sul & Sim \\
\hline Argentina & Sim \\
\hline Austrália (Western Austrália) & Sim \\
\hline Bolívia & Sim \\
\hline Brasil & Sim \\
\hline Canadá (Ontário) & Sim \\
\hline Chile & Sim \\
\hline China & Sim \\
\hline Costa do Marfim & Sim \\
\hline Equador & Sim \\
\hline Estados Unidos (Colorado) & Sim \\
\hline Filipinas & Sim \\
\hline Gana & Sim \\
\hline Guiana & Sim \\
\hline Indonésia & Sim \\
\hline Kazaquistão & Sim \\
\hline México & Não \\
\hline Papua Nova Guiné & Sim \\
\hline Peru & Sim \\
\hline Polônia & Sim \\
\hline Suriname & Sim \\
\hline Tanzânia & Sim \\
\hline
\end{tabular}

Quadro 2: Possível aplicação da depreciação a equipamentos mineiros típicos (países selecionados).

Fonte: Andrews-Speed(2000); Mackenzie (1998); Otto (2000, 2001); Otto; Cordes (2002); Parsons (1998, 2000). 
Por outro lado, a instalação do empreendimento mineiro requer a importação de equipamentos. A taxação sobre a importação desses equipamentos ou mesmo o recolhimento, em âmbito nacional, de impostos vinculados ao valor agregado deixam o empreendimento mineiro também muito vulnerável às políticas tributárias relacionadas a esses itens. A cobrança de tributo sobre valor agregado - como o Imposto sobre Circulação de Mercadorias e Serviços (ICMS) no Brasil -, baseada hipoteticamente em uma alíquota de 10\%, que incida sobre os equipamentos nacionais necessários à montagem da mina, ou mesmo uma taxação de $10 \%$ sobre a importação de equipamentos, implicaria custos de até US\$50 milhões para uma mina cujos custos de implantação envolvam a compra de equipamentos da ordem de US\$ 500 milhões.

Diante da expressividade que esses tributos podem assumir na composição de custos de um empreendimento, as empresas mineradoras, como padrão de atuação, reivindicam compensações de ordem tributária. Como os depósitos de classe mundial representam possibilidades de renda, a médio prazo, acima de US\$ 100 milhões (MACKENZIE, 1998), os governos da maioria dos países, no intuito de atrair investimentos, provêem algum tipo de incentivo fiscal relacionado à compra de equipamento, particularmente se o produto de mina é destinado ao mercado externo (OTTO, 2001). A Indonésia, por exemplo, conta com instrumentos fiscais que possibilitam à mineradora ser isentada do imposto sobre valor agregado, no período de edificação das instalações da mina e da infra-estrutura. A empresa mineradora conta também com incentivos fiscais que Ihe permitem importar maquinaria e equipamentos com isenção de impostos aduaneiros. Trata-se de uma prática fiscal corrente, visto que muitos governos reconhecem a importância da mineração e provêem vários incentivos fiscais para acelerar a recuperação, por parte da empresa, dos custos de implantação (OTTO, 2001).

\section{2 - INVESTIMENTOS DE RISCO E DE LONGO PRAZO E REPERCUSSÕES SOBRE A TRIBUTAÇÃO}

Em comparação com as demais atividades econômicas, a mineração envolve risco alto, não somente na fase das pesquisas geológicas, mas também nas demais fases do ciclo de vida do projeto - a fase de desenvolvimento mineiro e a fase de produção. Esse nível de risco faz com que, para capitais investidos nessa atividade, sejam buscadas taxas de retorno superiores às das demais atividades. Para Parsons (2000), 
como regra geral, o piso aceitável de retorno de investimento em um empreendimento mineiro deve oscilar entre 15\% e 18\%. Segundo o autor, uma jazida de ouro, de porte médio, situada no estado de Colorado, nos Estados Unidos, em dez anos de produção, teria uma taxa de retorno média de 14,14\%. Essa taxa de retorno pode ser bastante atraente em outras atividades econômicas; todavia, em razão dos elevados riscos da atividade mineira e desse nível de retorno, a exploração dessa jazida provavelmente não se efetivaria. Uma outra jazida, com as mesmas condições geológicas, situada no Chile, teria uma taxa de retorno de $18,34 \%$, estando, portanto, acima dos níveis de retorno que, segundo Parsons (2000), são capazes de compensar, do ponto de vista do capital, os risco desse tipo de atividade. Nesse caso, trata-se de uma diferença de retorno econômico que deveria ser imputada ao regime tributário do Chile. Com efeito, o já citado estudo de Mackenzie (1998) mostrou a existência, para empreendimentos mineiros no Chile, de uma taxa de retorno média de $25 \%$. Esse nível de retorno deve-se, em grande medida, às políticas tributárias praticadas naquele país, amplamente favoráveis aos mineradores. 0 autor estima que minas na Amazônia beneficiadas pela isenção ou pela redução da alíquota de IR possam ter uma taxa média de retorno superior a 30\% (Tabela 1; Gráfico 2).

A mineração é um investimento de longo prazo. Se as minas de metais preciosos, como as de ouro do igarapé Bahia, em Carajás, tiveram atividades que se estenderam por uma década, a exploração de minas de metais básicos, como as de bauxita em Trombetas, pode estender-se por mais de cinco décadas, e as minas de hematita de Carajás podem ultrapassar um século de lavra. A tividades econômicas que têm previsão de duração tão longa podem sofrer variações em elementos importantes para o empreendimento, como preço do mineral, custos operacionais, impostos, etc. Essas variações em parâmetros fundamentais fazem com que o risco desse tipo de projeto seja elevado.

Outra possibilidade, em termos tributários, a que se recorre para se reduzirem os impactos das oscilações dos preços das commodities minerais sobre a rentabilidade dos capitais investidos na mineração é a compensação futura ou mesmo, em al guns casos, retroativa dos prejuízos desses capitais (Quadro 3).

Em decorrência do longo tempo de duração dos investimentos, as empresas mineradoras procuram negociar mecanismos para minimizar a variação da tributação incidente sobre o empreendimento ao longo de sua existência, buscando, assim, reduzir um fator de risco. Parsons (2000) mostra que alguns países objetivam dar mais estabilidade às regras tributárias a que se sujeita o empreendimento, 
incorporando o regime de imposto em um contrato bilateral entre o governo e a empresa mineradora. Esse tipo de prática foi adotado, por exemplo, na Indonésia, onde um contrato assinado entre o governo e a companhia mineira, cujos termos fundamentais são aprovados no parlamento e são de amplo domínio público, estabelece que, em caso de alterações na legislação, o governo garante, para o período que abarca a vida da mina, a cobertura dos direitos e obrigações da companhia, inclusive os de ordem tributária. Parsons (1998) lembra ainda que alguns países têm um regime híbrido: há um regime de tributação que se aplica como sistema padrão à maioria das minas, mas certas minas estão sujeitas a regras tributárias fixadas de forma excepcional, o que é feito mediante um contrato bilateral firmado entre o governo e a empresa mineradora. Na Guiana, por exemplo, os impostos que se aplicam à mina de Omai são determinados em um contrato firmado entre a mineradora e o governo.

\begin{tabular}{l|c|c}
\hline \multicolumn{1}{c|}{ País } & Com ganhos futuros & Retroativamente \\
\hline Africa do Sul & Sim & Não \\
\hline Argentina & Sim & Não \\
\hline Austrália (Western Austrália) & Sim & Não \\
\hline Bolívia & Sim & Não \\
\hline Brasil & Sim & Não \\
\hline Canadá (Ontário) & Sim & Sim \\
\hline Chile & Sim & Não \\
\hline Equador & Sim & Sim \\
\hline Estados Unidos (Colorado) & Sim & Sim \\
\hline Filipinas & Sim & Não \\
\hline México & Sim & Não \\
\hline Peru & Sim & Não \\
\hline
\end{tabular}

Quadro 3: Possibilidade de compensação dos prejuízos.

Fonte: Andersen (2001); Andrews-Speed (2000); Andrews-Speed; Rogers (1999); Mackenzie (1998); Otto (1998, 2000, 2001); Otto; Cordes (2002); Parsons (1998, 2000).

\section{3 - COMPENSAÇÃO PELO ESGOTAMENTO DE UM RECURSO NÃO RENOVÁVEL}

A mineração tem outra especificidade em relação à maioria das atividades econômicas, pois explota recursos minerais que não mais estarão à disposição da sociedade. Trata-se de uma especificidade que tem repercussões diretas nos encargos que incidem sobre essa atividade. Assim, em termos mundiais, há aceitação quase 
generalizada da idéia de que a mineração, em função de suas peculiaridades, deve ser taxada de forma adicional, pois, ao utilizar recurso que não mais estará à disposição da sociedade, deve oferecer uma compensação pela perda permanente daquele bem, ou seja, devese cobrar um encargo compulsório, como forma de incluir o custo da exaustão de um patrimônio social.

Logo, no que se refere aos encargos incidentes sobre a exploração dos recursos minerais, além da tributação normal a que todas as atividades produtivas estão sujeitas, um encargo extra é necessário para que a sociedade se aproprie, pelo menos, de parte do valor do recurso, cujo aproveitamento é concedido de forma exclusiva a uma empresa.

Entende-se que a diferenciação nos encargos públicos incidentes sobre as atividades de mineração justifica-se assim pelo fato de a formação das jazidas minerais não envolver esforço humano, as jazidas podem ser consideradas como presentes fortuitos proporcionados pela natureza. Sendo ofertadas pela natureza, não deveriam ser propriedade de ninguém especificamente, deveriam ser propriedade da sociedade em geral, representada pelo Estado. 0 benefício resultante de seu aproveitamento deveria, portanto, ser partilhado pela sociedade em geral, e não apropriado apenas por quem realiza o seu aproveitamento.

Esse entendimento dos recursos minerais como um patrimônio social tem-se manifestado, em termos mundiais, no princípio da separação da propriedade do solo da propriedade do subsolo e no princípio da soberania permanente e inalienável do Estado sobre os recursos minerais existentes em seu território.

Para conceder a terceiros o direito de aproveitamento exclusivo de recursos minerais de sua propriedade, o Estado normalmente exige alguma forma de pagamento, assim como faria o proprietário de qualquer outro recurso. Esse pagamento é geralmente denominado royalty pagamento feito ao Estado pelo direito de uso dos recursos minerais de sua propriedade. Embora possa ter uma forma análoga e, em alguns países, até receber o nome de imposto, conceitualmente um royalty não é um imposto.

Ressalte-se que a propriedade dos bens minerais varia de país para país. Em alguns poucos países, o proprietário fundiário pode cobrar royalties pela exploração mineral, mas, na ampla maioria dos casos, os recursos minerais são bens do próprio Estado nacional ou de coletividades por ele representadas. Assim, freqüentemente, cabe ao Estado nacional estabelecer a cobrança de royalties. 
Em alguns países, os bens minerais são de propriedade das unidades que compõem o Estado nacional (províncias, estados federados, etc.); nesse caso, cabe a elas a tributação pela exploração. $\mathrm{Na}$ Malásia, por exemplo, a maioria das províncias é proprietária das reservas minerais e, dentro de suas jurisdições, estabelecem regras para o pagamento de royalties. Na Austrália, há diversos regimes de royalties em função da forma como se edifica a sua estrutura legal. A legislação australiana relativa à mineração é estabelecida no âmbito dos estados ou territórios, inclusive a relacionada aos royalties; cada estado federado estabelece, portanto, seus próprios regimes de compensação pela depleção de recursos minerais. No Canadá, outro grande produtor mundial de minérios, as províncias também gozam de autonomia para legislar sobre atividades de mineração em seu território e, por isso, no âmbito infranacional, cobram royalties como também imposto sobre a renda auferida pela empresa mineradora; elas estabelecem diferentes políticas para a cobrança de encargos adicionais de empresas de mineração, com o propósito de compensar a província pela depleção de recursos minerais que lhe pertencem. Nos Estados Unidos, royalties são pagos ao governo federal caso seja efetivada a exploração mineral em terras que pertençam ao governo federal. Os royalties variam de $12 \%$ a $14 \%$. No âmbito estadual, há uma multiplicidade de "impostos indenizatórios", análogos aos royalties, cujas alíquotas e base de cálculo variam de estado para estado: em alguns estados, os royalties incidem nos preços de venda do produto; noutros, nas receitas líquidas das empresas ou mesmo em um valor específico sobre a tonelada do mineral explorado. Em termos gerais, naquele país, as alíquotas de "impostos indenizatórios" cobrados pelos estados oscilam entre $1 \%$ e $7 \%$.

De acordo com Otto (2001), nas últimas décadas, surgiu, em alguns países de passado colonial, um debate sobre os direitos de propriedade de reservas minerais de povos ancestrais, de povos indígenas que vivem ou viveram em épocas passadas em áreas onde se localizam reservas minerais. 0 reconhecimento dos direitos de populações ancestrais sobre bens minerais implicou, em alguns casos, a adoção de instrumentos legais distintos para prover uma compensação. Em determinados estados da Austrália, por exemplo, foi delegada às populações aborígines a prerrogativa de negociar privadamente pagamentos pela prospecção e de royalties compensatórios relacionados à mineração em terras dessas populações tradicionais. Em outros países, como nas Filipinas e em alguns estados federados dos Estados Unidos, parcelas dos royalties arrecadados pelo Estado são revertidos às populações nativas. 
Pode-se dizer que, em termos gerais, tradicionalmente, o sistema de cobrança de royalties assumiu duas formas básicas: o royalty específico e o royalty ad valorem.

0 royalty específico consiste no pagamento de um valor fixo por unidade produzida. Suas grandes vantagens são a estabilidade da receita, a simplicidade, a facilidade de administração e a dificuldade de sonegação. Suas desvantagens, porém, são consideráveis. Sendo insensível aos custos, o royalty específico penaliza os minérios de teor mais baixo, incentivando a lavra seletiva. Nesse caso, para a empresa de mineração, o royalty é um custo variável adicional que provoca 0 aumento do teor de corte e, conseqüentemente, a redução das reservas recuperáveis, podendo até inviabilizar o aproveitamento do depósito. Esse resultado depende da uniformidade do teor, sendo mais intenso nos casos em que ele está sujeito a grande variação. 0 royalty específico é completamente insensível às variações da receita e à existência de renda econômica. A Índia utiliza, em certos casos, um sistema de royalty específico e, para não incentivar a lavra seletiva, escalona o valor do royalty em função do teor contido no minério. No caso do minério de ferro, o governo cobra 24,50 rúpias por tonelada de minério com teor superior a $65 \%$ e 14,50 rúpias por tonelada de minério com teor de ferro superior a $62 \%$, ao que se segue uma gradação de royalties de caráter específico em função do teor. Esses valores equivaleriam, nos dois casos citados, respectivamente a US\$ 0,54 e a US\$ 0,32por tonelada de minério de ferro.

Já o royalty ad valorem incide na forma de uma alíquota sobre o preço de venda do mineral. Propicia razoável grau de estabilidade à receita e, em grande número de casos, implica simplicidade e facilidade de administração. No entanto, há situações em que pode haver considerável dificuldade na determinação do valor tributável. Embora varie com a receita, o royalty ad valorem também é um custo variável para o produtor. A China, por exemplo, cobra royalties ad valorem em seu território sobre a produção mineral.

Em âmbito mundial, há casos nos quais tanto o royalty específico como o royalty ad valorem podem ser estabelecidos mediante licitação ou por meio de negociação, projeto a projeto. No entanto, é bastante comum sua imposição pelo governo na forma de regras gerais, sem nenhuma relação com as condições específicas de cada projeto, embora podendo considerar variações para diferentes grupos de substâncias minerais.

Os royalties tradicionalmente eram específicos ou ad valorem, mas têm tomado formas novas. Durante as últimas décadas, alguns países 
ou entes federados passaram a enfatizar sistemas de cobrança baseados nos lucros das empresas mineradoras, direcionando assim os fundamentos da cobrança dos royalties para o nível de lucratividade adicional das empresas mineradoras, e não para o valor das vendas ou para uma taxação específica.

Trata-se nesse caso da possibilidade da cobrança de um royalty da empresa mineradora pela exploração de recursos naturais não para compensar pela depleção, mas pelo fato de que a valorização do recurso natural pode ensejar para a empresa mineradora a geração de uma renda "diferencial" da qual empresas de outros ramos não se beneficiariam; dentro do mesmo ramo, certas empresas poderiam auferir rendas "diferenciais" baseadas na estrutura geológica do jazimento, na localização, na qualidade do minério, etc. - um diferencial que deveria assim ser a base para a cobrança do royalty, ou seja, para o estabelecimento de uma taxação adicional sobre a lucratividade das mineradoras. Bunker (2000), entre outros autores, argumenta que a cobrança do royalty poderia ser aperfeiçoada do ponto de vista governamental, se fosse adotado este como o princípio de cobrança de royalties. Ele defende que, em lugar de tributar a receita obtida na mineração, como no caso da Compensação Financeira pela Exploração de Recursos Minerais (CFEM), o governo poderia ter uma participação no resultado líquido da mina, ou seja, na renda econômica que ela fosse capaz de gerar.

Todavia, há argumentos contrários a esse princípio que vincula a cobrança dos royalties a uma sobretaxa sobre a lucratividade da mina. De acordo com o primeiro argumento, as companhias mineradoras, ou mesmo as minas em termos individuais, nem sempre geram lucros; assim, uma política de estabelecimento de royalties vinculados à lucratividade poderia não surtir efeito, uma vez que, diante da possibilidade de não realização de lucros, não há nenhuma garantia de que o Estado arrecadaria qualquer compensação baseada na rentabilidade das operações, apesar da depleção dos recursos minerais.

Alguns estados da Austrália adotam critérios que conjugam a taxação de parte dos lucros das empresas mineradoras a título de royalty pela exploração de recursos minerais com a cobrança de royalties ad valorem e de royalties específicos, compondo uma base híbrida para o estabelecimento da compensação financeira para a sociedade pela depleção de certos recursos minerais.

O fato é que, em termos mundiais, há inúmeros modos de determinar um royalty. Muitos são bastante diretos, outros, nem tanto. 
No entanto, há concordância bastante ampla de que a depleção de reservas minerais requer uma compensação financeira para a sociedade (Quadro 4).

\begin{tabular}{l|c}
\hline \multicolumn{1}{c|}{ País } & Royalties \\
\hline Africa do Sul & Não \\
\hline Argentina & Sim \\
\hline Austrália (Western Austrália) & Sim \\
\hline Bolívia & Sim \\
\hline Brasil & Sim \\
\hline Canadá (Ontário) & Sim \\
\hline Chile & Não \\
\hline China & Sim \\
\hline Costa do Marfim & Sim \\
\hline Equador & Sim \\
\hline Estados Unidos (Colorado) & Sim \\
\hline Filipinas & Sim \\
\hline Gana & Sim \\
\hline Guiana & Sim \\
\hline Indonésia & Sim \\
\hline Kazaquistão & Sim \\
\hline México & Não \\
\hline Papua Nova Guiné & Não \\
\hline Peru & Não \\
\hline Polônia & Sim \\
\hline Suriname & Sim \\
\hline Tanzânia & Sim \\
\hline
\end{tabular}

Quadro 4: Cobrança de royalties minerais (países selecionados). Fonte: Andrews-Speed (2000); Mackenzie (1998); Otto ( 2000, 2001); Otto; Cordes (2002); Parsons (1998, 2000).

Estudos de Kumar (1991) indicam que, na ótica governamental, o royalty ad valorem, ao ser comparado com outras formas de royalties, satisfaz aos critérios de estabilidade na geração de receitas, de facilidade de arrecadação e de capacidade de arrecadar rapidamente; conforme a forma de sua cobrança, pode satisfazer à progressividade e à justiça distributiva. A comparação aponta, entretanto, que o royalty ad valorem não satisfaz ao critério da neutralidade, que só poderia ser atendido por um royalty incidente em um percentual sobre o lucro (Quadro 5). 


\begin{tabular}{|c|c|c|c|c|c|c|}
\hline & 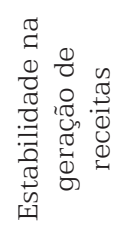 & $\begin{array}{l}0 \\
0 \\
0 \\
0 \\
0 \\
0 \\
0 \\
0 \\
0 \\
0 \\
0 \\
0\end{array}$ & 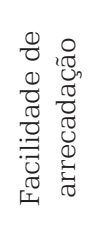 & 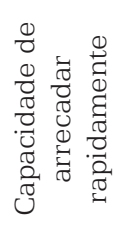 & 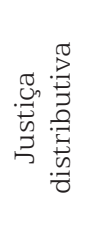 & 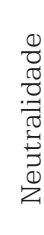 \\
\hline \multicolumn{7}{|l|}{ 1. Royalty } \\
\hline Valor fixo por toneladas & S & $\mathrm{N}$ & S & S & $\mathrm{P}$ & $\mathrm{N}$ \\
\hline $\begin{array}{l}\text { Percentual sobre valor de } \\
\text { produção }\end{array}$ & S & $\mathrm{P}$ & S & S & $\mathrm{P}$ & $\mathrm{N}$ \\
\hline 2. Imposto sobre renda & $\mathrm{P}$ & $\mathrm{P}$ & $\mathrm{P}$ & $\mathrm{P}$ & S & $\mathrm{P}$ \\
\hline $\begin{array}{l}\text { Depreciação acelerada do } \\
\text { capital }\end{array}$ & $\mathrm{N}$ & $\mathrm{N}$ & $\mathrm{P}$ & N & S & $\mathrm{N}$ \\
\hline Depleção & $\mathrm{N}$ & $\mathrm{N}$ & $\mathrm{N}$ & $\mathrm{N}$ & $\mathrm{P}$ & $\mathrm{N}$ \\
\hline $\begin{array}{l}\text { Depreciações de outras } \\
\text { ordens }\end{array}$ & $\mathrm{N}$ & $\mathrm{N}$ & $\mathrm{P}$ & $\mathrm{N}$ & $\mathrm{P}$ & $\mathrm{N}$ \\
\hline $\begin{array}{l}\text { Compensação de prejuízos } \\
\text { fiscais retroativamente ou } \\
\text { em ganhos futuros }\end{array}$ & $\mathrm{N}$ & $\mathrm{N}$ & $\mathrm{P}$ & $\mathrm{N}$ & S & S \\
\hline $\begin{array}{l}\text { 3. Impostos adicionais } \\
\text { (baseados na } \\
\text { lucratividade) }\end{array}$ & $\mathrm{N}$ & S & $\mathrm{N}$ & $\mathrm{P}$ & S & S \\
\hline $\begin{array}{l}\text { 4. Impostos sobre } \\
\text { dividendos ou } \\
\text { distribuição de lucros }\end{array}$ & $\mathrm{P}$ & $\mathrm{P}$ & S & $\mathrm{P}$ & S & S \\
\hline
\end{tabular}

\begin{tabular}{|l|l} 
S & $\begin{array}{l}\text { Satisfaz aos } \\
\text { interesses }\end{array}$
\end{tabular}



Quadro 5: Avaliação de instrumentos fiscais usando critérios governamentais.

Fonte: Kumar (1991).

Todavia, o mesmo estudo de Kumar (1991) indica que, em termos de descentralização da receita, que tem grande relevância para, potencialmente, articular mineração e formação de fundos públicos para impulsionar processos desenvolvimento regional, um royalty ad valorem é apropriado ao propósito da descentralização da receita para a esfera federal, para a estadual e, possivelmente, para a esfera municipal; já um royalty incidente sobre um percentual do lucro, em termos de 
descentralização, seria apropriado para a esfera federal, poderia ser adequado em termos de descentralização fiscal para a esfera estadual, mas seria pouco apropriado na esfera municipal (Quadro 6).

\begin{tabular}{l|c|c|c}
\hline \multirow{2}{*}{ Tipo de tributo } & \multicolumn{3}{c}{ Esfera de governo } \\
\cline { 2 - 4 } & Nacional & Estadual & Municipal \\
\hline Imposto incidente sobre renda ou lucro & $\mathrm{A}$ & $\mathrm{P}$ & $\mathrm{X}$ \\
\hline Tributação incidente sobre importação & $\mathrm{A}$ & $\mathrm{X}$ & $\mathrm{X}$ \\
\hline Tributação incidente sobre exportação & $\mathrm{A}$ & $\mathrm{X}$ & $\mathrm{X}$ \\
\hline Royalty (um percentual incidente sobre lucro) & $\mathrm{A}$ & $\mathrm{P}$ & $\mathrm{X}$ \\
\hline Royalty (um percentual sobre valor de produção) & $\mathrm{A}$ & $\mathrm{A}$ & $\mathrm{P}$ \\
\hline Royalty (valor fixo por tonelada) & $\mathrm{A}$ & $\mathrm{A}$ & $\mathrm{A}$ \\
\hline Taxas de licenciamento & $\mathrm{A}$ & $\mathrm{A}$ & $\mathrm{A}$ \\
\hline Taxas pelo uso da terra & $\mathrm{A}$ & $\mathrm{A}$ & $\mathrm{A}$ \\
\hline $\begin{array}{l}\text { Impostos incidentes sobre dividendos, distribuição de lucros } \\
\text { e remessas para o exterior }\end{array}$ & $\mathrm{A}$ & $\mathrm{X}$ & $\mathrm{X}$ \\
\hline Impostos sobre valor agregado & $\mathrm{A}$ & $\mathrm{P}$ & $\mathrm{X}$ \\
\hline Impostos sobre consumo e vendas & $\mathrm{A}$ & $\mathrm{P}$ & $\mathrm{P}$ \\
\hline Taxas aduaneiras (selos) & $\mathrm{A}$ & $\mathrm{A}$ & $\mathrm{A}$ \\
\hline Impostos sobre propriedade (baseados no valor da mina) & $\mathrm{A}$ & $\mathrm{A}$ & $\mathrm{A}$ \\
\hline Impostos incidentes sobre folha de pagamento & $\mathrm{A}$ & $\mathrm{P}$ & $\mathrm{X}$ \\
\hline Sobretaxas & $\mathrm{A}$ & $\mathrm{A}$ & $\mathrm{A}$ \\
\hline Taxas decorrentes do uso da infra-estrutura & $\mathrm{A}$ & $\mathrm{A}$ & $\mathrm{A}$ \\
\hline
\end{tabular}

$\begin{array}{lll}\text { A Apropriado } \mathrm{P} & \text { Positivamente apropriado } \mathrm{X} & \begin{array}{l}\text { Pouco } \\ \text { apropriado }\end{array}\end{array}$

Quadro 6: Tributação e sua apropriação em termos de descentralização fiscal.

Fonte: Kumar (1991)

\section{4 - A COMPENSAÇÃO FINANCEIRA PELA EXPLORAÇÃO MINERAL NO BRASIL}

No Brasil, as características peculiares fiscais da mineração foram expressamente reconhecidas no arcabouço legal nacional por meio do estabelecimento do Imposto Único Sobre Minerais (IUM), que foi instituído pela Constituição de 1946, embora só tenha começado a vigorar em 1964, após ter sido regulamentado por legislação específica. O IUM incidia sobre a extração, a circulação, a distribuição e o consumo de minerais do País. 0 imposto não podia incidir mais de uma vez, ou seja, apenas uma dessas operações era tributada. Além disso, outro 
imposto não era aplicável a essas operações. O IUM era, portanto, análogo a um royalty ad valorem.

Dada a dificuldade de definir o valor tributável quando havia uma variação acentuada no valor do mineral, quando esse valor era muito baixo ou quando havia transferência do mineral entre empresas associadas, houve a necessidade de estabelecer pautas, ou seja, de discriminar os preços dos minerais sobre os quais deveria incidir o IUM. No caso de bens minerais cujos preços, para efeito de cálculo do IUM, eram estabelecidos pelos órgãos governamentais, o imposto passava a assemelhar-se a um royalty específico.

A alíquota básica do IUM para as substâncias minerais destinadas ao mercado interno era de $15 \%$ da base de cálculo (geralmente o preço de venda). Nas exportações, a alíquota geral era de $4 \%$. Havia alíquotas especiais para metais nobres, pedras preciosas, pedras semipreciosas lapidáveis e carbonados, inclusive quando destinados à exportação; nesse caso, a alíquota era de 1\%. No caso de minério de ferro e de manganês destinados ao exterior, a alíquota era de 7,5\%.

A Constituição Federal de 1988 adotou o princípio segundo o qual os recursos minerais são de propriedade da União e seu aproveitamento é um privilégio que requer uma compensação por parte de quem tem o direito exclusivo de aproveitamento desses recursos. Em decorrência desse princípio, extinguiu o IUM, colocou os minerais no campo de incidência do ICMS e criou a compensação financeira e a participação no resultado da exploração de recursos minerais.

A regulamentação do artigo 20 da Constituição, por meio das leis n. 9 7990, de 1989, e n.o 8001, de 1990, e do Decreto n.ㅇ 01/91, estabeleceu a Compensação Financeira pela Exploração de Recursos Minerais (CFEM). Trata-se, efetivamente, na forma como foi regulamentada, de um royalty ad valorem. Assim, atualmente, a compensação financeira devida à sociedade brasileira pela exploração de seus bens minerais efetiva-se por meio de um royalty ad valorem, como efetivamente é a CFEM.

Todavia, na prática, nas últimas décadas, foi reduzida a proporção, em relação ao preço de venda do minério, do montante da compensação devida, em termos financeiros, pela exploração de recursos minerais. Isso se deve, entre outros fatores, ao estabelecimento na legislação vigente de alíquotas muito mais baixas do que as que vigoraram com 0 IUM. Além disso, a legislação não determinou com clareza inequívoca a efetiva base de cálculo e o ponto de incidência da CFEM, o que ensejou um número significativo de demandas judiciais. 
Nesse caso, comparando-se as alíquotas da CFEM com as dos royalties cobrados em outros países, verifica-se que as do Brasil são bastante inferiores às que incidem sobre minerais em outros países.

Essas diferenciações, em termos de alíquotas, são significativas. Basta tomar como exemplo dois produtos minerais, o minério de ferro e a bauxita, que foram responsáveis, respectivamente, por $46,79 \%$ e $9,15 \%$ da CFEM recolhida no período de janeiro de 1996 a dezembro de 2002, representando, portanto, aproximadamente, 56\% dos $\mathrm{R} \$ 722,3$ milhões (em valores históricos) da CFEM recolhida no período .

No caso do minério de ferro, os maiores produtores mundiais são o Brasil, que em 2001 produziu 208 milhões de toneladas, e a Austrália, que, no mesmo ano, produziu 180 milhões de toneladas de minério. No Brasil, a alíquota da CFEM é de $2 \%$ sobre o faturamento líquido da venda desse produto mineral, o que permite excluir despesas de transporte e seguro. J á a alíquota do royalty ad valorem que incide sobre as vendas de mineradoras instaladas na Austrália é muito superior. No caso da Western Australia, onde se localizam empresas responsáveis pela exploração de $97 \%$ do minério do país, a alíquota de royalty tem como piso $5 \%$ sobre o valor de venda de concentrados e finos de minério de ferro, atingindo 7,5\% do valor das vendas desse minério. Trata-se de royalties que são pagos por empresas que vendem, como as brasileiras, seus produtos no mercado global e que compensam de forma desigual as sociedades nacionais pela depleção dos recursos minerais. As empresas instaladas no Brasil e as instaladas na Austrália são responsáveis por aproximadamente $62 \%$ do minério de ferro e de seus concentrados exportados no mundo. As empresas baseadas na Austrália foram responsáveis, em 2000, pela exportação de 157,2 milhões de toneladas de minério de ferro e seus concentrados, e as empresas em operação no Brasil, por 156,8 milhões de toneladas.

Quanto à produção de bauxita, os maiores produtores mundiais são a Austrália, que, em 2000, foi responsável pela produção de 53,8 milhões de toneladas, e a Guiné, responsável por 17,95 milhões de toneladas, seguidas do Brasil, que, no mesmo ano, foi o terceiro maior produtor mundial, com 13,22 milhões de toneladas, e da J amaica, que produziu 11,12 milhões de toneladas. A produção desses quatro países em conjunto é responsável por mais de $70 \%$ do volume global de bauxita extraída no globo.

No Brasil, a compensação financeira pela exploração da bauxita é de $3 \%$ e incide sobre o faturamento líquido da venda do produto mineral, um royalty muito inferior ao cobrado pela Austrália das empresas responsáveis pela exploração da bauxita lá instaladas. 
Como se indicou anteriormente, a legislação relativa aos royalties na Austrália varia de estado para estado. Lá a exploração da bauxita está concentrada em dois estados e um território: Queensland, Western Australia e Northern Territory. No primeiro deles, a taxa de royalty paga sobre a bauxita exportada é de 10\% sobre o valor de venda free on board (FOB), ou seja, o preço da mercadoria dentro do navio sem qualquer desconto; no caso de vendas internas, a alíquota do royalty sobre a bauxita é de $5 \%$ sobre o preço de venda. No segundo estado, os royalties pela depleção da bauxita são de 7,5\% sobre o preço de venda (FOB), caso o produto se destine à exportação; quando a bauxita se destina ao mercado interno, é permitido que a empresa desconte os custos de transporte, mas a alíquota de 7,5\% é mantida. Em Northern Territory, a alíquota de royaltyé de $18 \%$ sobre o valor das vendas, sendo, entretanto, permitido às mineradoras deduzir custos operacionais e de exploração.

No que se refere à Guiné, segunda maior produtora mundial de bauxita, onde o estado nacional legisla sobre os royalties e deles se apropria, as alíquotas são de $10 \%$ sobre o preço de venda (FOB); essa alíquota pode ser reduzida pela metade, passando a ser de $5 \%$, caso se trate da venda de alumina.

No caso da J amaica, outro grande produtor mundial, o royaltylá cobrado é do tipo específico, ou seja, consiste no pagamento de um valor fixo, que no caso da bauxita é de US\$ 0,50 (cinqüenta centavos de dólar americano) por tonelada de bauxita exportada; caso haja a exportação de alumina e não de bauxita, o valor continua o mesmo, só que incide sobre o volume de bauxita a que, presumidamente, se recorreu para a produção da alumina.

Nesse especial, há, aparentemente, uma lógica que repercute na dimensão da compensação financeira que a sociedade recebe e que se vincula à organização do Estado Nacional e às instituições que legislam e se apropriam dos royalties. No caso da Austrália, como a competência para legislar sobre a compensação pela depleção de recurso mineral, bem como para arrecadar e aplicar os recursos originários dos royalties é das unidades intranacionais, a taxação tende a ser mais elevada. Quanto à Guiné e à J amaica, é o próprio Estado nacional que legisla, arrecada e aplica os royalties. Nesse caso, há também interesse de se estabelecer uma compensação pela exploração dos recursos minerais mais elevada.

Já no caso do Brasil, onde a competência para legislar é da União e a aplicação dos recursos cabe majoritariamente a entes intranacionais (estados e municípios), há uma tendência para rebaixar as alíquotas dos royalties. Assim, por um fenômeno de apropriação desigual do poder político (BOSIER, 1996), estabeleceu-se no Brasil uma política de compensação pela exploração mineral, que, por um lado, prejudica os 
entes federados (especialmente os municípios) nos quais se concentram as maiores minas e, por outro, atende os interesses de outros entes da federação. Trata-se de uma realidade institucional na qual a política de compensação pela exploração mineral aparentemente reflete os interesses de todos os entes federados, mas, de fato, representa apenas $o$ interesse dos mais poderosos.

Ao se observar a estrutura de custos vinculada à valorização da bauxita na região do rio Trombetas, nota-se que os custos relativos aos royalties representam tão-somente $2.65 \%$ do faturamento total da Mineração Rio do Norte (MRN) e que, em 2003, os custos operacionais representavam $43.71 \%$ do faturamento, o que o permitiu que a empresa tivesse lucro líquido que correspondeu a $39.34 \%$ do faturamento bruto. Nesses termos, a equiparação das alíquotas de royalties àquelas cobradas pelos maiores exportadores mundiais de bauxita não é compatível nem com os níveis de lucratividade da empresa, nem mesmo com a competitividade do produto em termos internacionais (Tabela 2).

Tabela 2: Indicação da receita, despesas e lucros da Mineração Rio do Norte, em 2003.

\begin{tabular}{lcrr}
\hline \multicolumn{1}{c}{ Itens } & US\$ milhões & $\%$ & US\$/t \\
\hline Receita bruta das vendas em 2003 & 288,99 & 100,00 & 20,50 \\
Impostos incidentes sobre as vendas & $-15,79$ & $-5,47$ & $-1,12$ \\
CFEM (royalties) & $-7,66$ & $-2,65$ & $-0,54$ \\
Custo dos produtos vendidos & $-126,31$ & $-43,71$ & $-8,96$ \\
Lucro bruto & 139,22 & 48,18 & 9,87 \\
Despesas operacionais & $-8,38$ & $-2,90$ & $-0,59$ \\
Lucro operacional & 130,84 & 45,28 & 9,28 \\
Despesas não operacionais & $-1,91$ & $-0,66$ & $-0,14$ \\
Lucro antes da tributação & 128,93 & 44,61 & 9,14 \\
Imposto de renda & $-15,25$ & $-5,28$ & $-1,08$ \\
Lucro líquido do exercício & 113,68 & 39,34 & 8,06 \\
\hline
\end{tabular}

Fonte: Elaboração do autor, com base no relatório anual da MRN.

Taxa de conversão: $\mathrm{R} \$ 1,00$ equivalente a US\$ 0,34965.

Quando se levam em conta os custos que envolvem a valorização do minério de ferro em Carajás, percebe-se também que a compensação financeira pela exploração do minério de ferro em Carajás equivale a $1,80 \%$ dos valores de venda do minério no Porto de Itaqui, em São Luís, e os custos operacionais que envolvem a mercantilização desse minério representam 35\% do preço médio de venda (Tabela 3). 
Tabela 3: Estimativa de custos operacionais que envolveram, em termos médios, a valorização de minérios de ferro em Carajás, em 2003.

\begin{tabular}{lccc}
\hline \multicolumn{1}{c}{ Item } & US\$ milhões & US\$/t & $\%$ \\
\hline Valor bruto decorrente da venda dos & 748.00 & 16.40 & 100.00 \\
minérios de ferro de Carajás & 29.78 & 0.65 & 3.98 \\
Lavra e manutenção & 27.21 & 0.60 & 3.64 \\
Beneficiamento & 13.44 & 1.80 & 1.80 \\
CFEM (royalties) & 81.35 & 1.78 & 10.88 \\
Transporte ferroviário & 43.87 & 0.96 & 5.87 \\
Movimentação de carga e embarque & 264.31 & 5.78 & 35.34 \\
Custos operacionais, médios, dos minérios & \multirow{2}{*}{ de ferro embarcados no porto de Itaqui } & & \\
\hline
\end{tabular}

Fonte: Elaboração do autor, com base em dados fornecidos por funcionários da Diretoria de Ferrosos da CVRD.

Diante da composição de custos do minério de ferro, anteriormente indicada, também é possível afirmar-se que não há óbice, em termos microeconômicos, a que as alíquotas de royalties cobradas sobre a exploração do ferro sejam equiparadas às que são devidas pelas empresas mineradoras que operam noutros países e que são responsáveis pelo abastecimento do mercado mundial. Mesmo quando se levam em conta os custos dos fretes para mercados transoceânicos, é viável manter a competitividade e a lucratividade da exploração do minério brasileiro no caso de uma eventual ampliação dos royalties.

\section{CONSIDERAÇÕES FINAIS}

As alíquotas de royalties existentes no Brasil, como compensação financeira pela exploração mineral, são as mais baixas entre os principais países exportadores de bens de origem mineral, o que, do ponto de vista analítico, deve-se mais a uma apropriação desigual do poder político no Brasil do que a uma restrição econômica.

$\mathrm{Na}$ definição da extensão da tributação das atividades voltadas para a valorização de recursos minerais e das possibilidades de se usar essa compensação financeira para impulsionar processos de desenvolvimento local, tem grande relevância o fato de o ente público ser o responsável pelo estabelecimento e pela forma de efetivação da distribuição intranacional dessa compensação. Trata-se de uma questão de grande importância, pois a depleção de reservas minerais mais acessíveis tem levado as novas minas a se situarem em locais mais 
distantes dos centros consumidores. Otto (2001) argumenta, com pertinência, que, em termos mundiais, a localização de minas em áreas distantes dos centros urbanos tem repercussão sobre as políticas que poderiam compensar financeiramente as populações que residiam nas proximidades das reservas minerais antes de sua exploração. Como freqüentemente as minas localizam-se em regiões com baixa densidade populacional e, por conseqüência, pequena expressão eleitoral, há pouco ou não há nenhum incentivo político para dirigir recursos decorrentes das atividades minerais para as comunidades afetadas e até mesmo para o governo local. Além da pouca expressão política e eleitoral, nas áreas mais afastadas dos grandes centros urbanos, a sociedade civil organizada é frágil.

Assim, no caso da Amazônia brasileira, o estabelecimento de uma política de tributação (lato sensu) articulada com o desenvolvimento da região é dificultada ou bloqueada por uma apropriação desigual do poder político. Reduz-se com isso o fornecimento aos entes federados dessa região de recursos que seriam destinados ao fortalecimento de processos de desenvolvimento fundamentados no estabelecimento de vantagens competitivas socialmente criadas e integradas ao uso sustentável da base natural da região.

Assim, se, por um lado, a renúncia fiscal pode beneficiar certas empresas mineradoras e, em nome do esforço exportador, em certos casos, favorecer a concorrência no mercado internacional, por outro, essa renúncia, especialmente se se leva em conta que os fundamentos de tal concessão são contratuais, poderia ser utilizada pelo poder público como um instrumento para estimular e induzir empresas mineradoras a adotar comportamentos que impulsionem processos de desenvolvimento de caráter endógeno, como a cooperação técnica interempresas, o estabelecimento de mecanismos de difusão tecnológica, a formação de cadeias de subcontratação que favoreçam o desenvolvimento local, etc.

Todavia, na Amazônia brasileira essas possibilidades não são exploradas, não havendo políticas públicas que associem a concessão de favores fiscais à adoção de comportamentos, por parte das empresas mineradoras, que possam resultar no estímulo ao desenvolvimento em termos locais e regionais. De fato, a oferta de favores fiscais está ligada a interesses de regiões mais desenvolvidas; em algumas delas, por meio de relações hierarquizadas e de apropriação desigual do poder político, impulsionam-se políticas públicas que representam seus interesses. No caso da mineração, sua capacidade de gerar grande volume de exportações de forma regular permite a obtenção de saldos favoráveis 
na balança comercial, o que atende aos interesses de regiões mais desenvolvidas. Contudo, esses resultados não necessariamente se coadunam com o reforço de dinâmicas que favoreçam o desenvolvimento em termos regionais e locais. Nesse contexto, favores fiscais são estabelecidos muito mais em decorrência de interesses extra-regionais do que, efetivamente, como políticas públicas voltadas para o desenvolvimento da região.

As políticas tributárias também evidenciam que a sociedade regional tem poder limitado para valer-se das especificidades da valorização de recursos minerais, pois o fato de as atividades de lavra, diferentemente de outras atividades econômicas, terem de, obrigatoriamente, ser desenvolvidas na área da ocorrência mineral - 0 que se costuma chamar rigidez locacional - poderia resultar no estabelecimento de dinâmicas sociais que possibilitassem a elevação da tributação decorrente da valorização dessas reservas. Especialmente a ampliação da CFEM (royalties), que poderia comportar uma dilatação da alíquota, sem comprometer a competitividade desses mercados, por causa das características dessas minas e dos mercados mundiais. Contudo, não é isso que ocorre.

Além disso, a rigidez locacional que caracteriza a exploração das minas não é utilizada para ampliar a tributação decorrente da característica peculiar das atividades mineiras. Por outro lado, a flexibilidade que as empresas possuem em relação às possibilidades de localização das instalações industriais nas quais se realizam etapas posteriores da transformação de bens minerais é utilizada de forma hábil para que estados nacionais e membros da federação recompensem com redução de impostos a instalação dessas empresas em seus territórios. Há, de tal forma, assimetrias nas negociações que envolvem, de um lado, a rigidez locacional da extração e do beneficiamento primário e, de outro, a flexibilidade das etapas posteriores de processamento dos minérios. 


\section{REFERÊNCIAS}

ANDREWS-SPEED, P., 2000. Reform of China's energy sector: slow progress to an uncertain goal. In: Zhuang, J ., Cook, S. and Yao, China's Economy in Transition Macmillan, London (in press),S. Editors, 2000.

BARHAM, Bradford; BUNKER, Stephen G.; O'HEARN, Denis (Ed.). States, Firms, and Raw Materials: the world economy and ecology of aluminum. Madison: University of Wisconsin, 1994.

BOSIER, S. Em busca do esquivo desenvolvimento regional: entre a caixa-preta e o projeto político, Planejamento e Políticas Públicas, Brasília, n. 13, p. 111- 142, jun. 1996.

BUNKER, S. G. J oint ventures em ambientes frágeis: o caso do alumínio na Amazônia. Novos Cadernos do NAEA, Belém, v. 3, n. 1, p. 5-46, jun. 2000.

FRASER INSTITUTE. Annual Report, Vancouver, BC, 2004.

KUMAR, Raj. Taxation for a Cyclical Industry. Resources Policy, 16(2), p. 135-148, J une 1991.

MACKENZIE, Brian W. Competitive Mining Tax Positions in South America. Paper presented in the Third International Gold Symposium, Lima, Peru, May 1998.

OTTO, J. M. Mining Taxation in Developing Countries. UNCTAD, Nov. 2000.

OTTO, J. M. Fiscal Decentralization and Mining Taxation. Washington, DC: World Bank Group Mining Department, Mar. 2001.

OTTO, J.M.; CORDES, J. The Regulation of Mineral Enterprises: A Global Perspective on Economics, Law and Policy.Westminster, Colorado, 2002.

PARSONS, B. Comparative Mining Tax Regimes: a summary of objectives, types and best practices. Global Energy \& Mining Group. PricewaterhouseCoopers, 1998. 
PARSONS, B. Mineral Taxation Policies in Asia. Asia Pacific Mining \& Quarrying Conference. Kuala Lumpur, Malaysia, Nov. 2000. PricewaterhouseCoopers, 2000. 